OPEN ACCESS

Edited by

Michael Benjamin Larkin, Baylor College of Medicine,

United States

Reviewed by:

Tipu Z. Aziz

John Radcliffe Hospital,

United Kingdom

Ashwin Viswanathan,

Baylor College of Medicine,

United States

*Correspondence:

Julie G. Pilitsis

jpilitsis@yahoo.com

Specialty section:

This article was submitted to

Cancer Pain,

a section of the journal

Frontiers in Pain Research

Received: 25 April 2021

Accepted: 23 July 2021

Published: 24 August 2021

Citation:

Sheldon BL, Bao J, Khazen O and

Pilitsis JG (2021) Spinal Cord Stimulation as Treatment for Cancer and Chemotherapy-Induced Pain

Front. Pain Res. 2:699993.

doi: 10.3389/fpain.2021.699993

\section{Spinal Cord Stimulation as Treatment for Cancer and Chemotherapy-Induced Pain}

\author{
Breanna L. Sheldon ${ }^{1}$, Jonathan Bao ${ }^{1}$, Olga Khazen ${ }^{1}$ and Julie G. Pilitsis ${ }^{1,2 *}$ \\ ${ }^{1}$ Department of Neuroscience and Experimental Therapeutics, Albany Medical College, Albany, NY, United States, \\ ${ }^{2}$ Department of Neurosurgery, Albany Medical Center, Albany, NY, United States
}

Neuropathic pain is a rampant disease exacting a significant toll on patients, providers, and health care systems around the globe. Neuromodulation has been successfully employed to treat many indications including failed back surgery syndrome (FBSS), complex regional pain syndrome (CRPS), phantom limb pain (PLP), radiculopathies, and intractable pelvic pain, among many others. Recent studies have also demonstrated efficacy for cancer-related pain and chemotherapy induced neuropathy with these techniques. Spinal cord stimulation (SCS) is the most commonly employed technique and involves implantation of percutaneous or paddle leads targeting the dorsal columns of the spinal cord with the goal of disrupting the pain signals traveling to the brain. Tonic, high frequency, and burst waveforms have all been shown to reduce pain and disability in chronic pain patients. Closed-loop SCS systems that automatically adjust stimulation parameters based on feedback (such as evoked compound action potentials) are becoming increasingly used to help ease the burden placed on patients to adjust their programming to their pain and position. Additionally, dorsal root ganglion stimulation (DRGS) is a newer technique that allows for dermatomal coverage especially in patients with pain in up to two dermatomes. Regardless of the technique chosen, neuromodulation has been shown to be cost-effective and efficacious and should be given full consideration in patients with chronic pain conditions.

Keywords: spinal cord stimulation, chronic pain, cancer pain, neuropathic pain, chemotherapy-induced pain, neuromodulation

\section{INTRODUCTION}

Chronic pain is a rampant disease affecting large swaths of global populations. The 2016 Global burden of disease study found that pain-related conditions, especially low-back and neck pain, are the leading cause of disability worldwide (1). Defined as intractable pain lasting $>3$ months, chronic pain is complex and difficult to treat. Neuropathic pain, a subtype of chronic pain, is related somatosensory nerve dysfunction and does not generally respond to opioid medications (2). Spinal cord stimulation (SCS) and dorsal root ganglion stimulation (DRGS) are two neuromodulatory techniques that have been shown to effectively treat neuropathic pain.

SCS is a form of neuromodulation that targets the spinal cord with electrical impulses to treat various pain conditions. It was first clinically utilized in 1967 by Shealy et al. to treat chronic pain induced by metastatic lung cancer (3). Since then, its applications include failed back surgery syndrome (FBSS), angina, critical limb ischemia, neuropathic pain and complex regional pain 
syndrome (CRPS) (4-8). The mechanism of action of SCS was based on the gate control theory postulated by Melzack and Wall in 1965, which proposed that stimulation of $A \beta$ fibers could attenuate or suppress pain signals traveling through $\mathrm{A} \delta$ and $\mathrm{C}$ fibers (9). However, new waveform stimulation techniques such as high-frequency stimulation (HFS) and burst stimulation have challenged this understanding, and the precise mechanism is much more nuanced (10-13). SCS usage has grown despite this gap in knowledge $(4-6,14,15)$, likely in part because it is costeffective compared to conventional medical management and primary spine surgery (16-20).

The success in treating other chronic pain disorders has led to SCS's use in treating cancer and chemotherapy-induced pain. Cancer-related pain affects more than $70 \%$ of patients and up to $40 \%$ of these patients report experiencing neuropathic pain (21). In multiple reports and retrospective reviews, SCS has been demonstrated to effectively treat cancer-related pain (22-27). Preliminary evidence from small case studies note significant improvements in pain relief from neuromodulation in patients with metastatic bone disease $(28,29)$. It has been also employed to treat chemotherapy-induced neuropathy (CIN) $(22,23)$. Cata et al. conducted a case study of two patients with CIN refractory to medication, who completed a successful trial of SCS and proceeded to permanent implant. Both patients showed improvement in pain scores, gait, flexibility, touch, sharpness detection, and reduction in medication, and improvements in gait and flexibility (23). Abd-Elsayed et al. similarly reports a case study in which a patient with breast cancer and CIN had excellent pain relief, improvement in daily functioning and sleep, and reduction of pain medication following SCS (22). CIN occurs in up to $40 \%$ of patients treated with agents known to have the potential for neurotoxicity and has been shown to significantly increase cancer survivor morbidity and healthcare expenditures (30). Given that pain and motor dysfunction are the most common reasons for discontinuation of chemotherapy prior to course completion--particularly with the frequently used platinum-containing compounds, vinca alkaloids, and taxols-SCS efficacy may be particularly significant (Table 1) (31-33). Though these initial results have been promising, large-scale RCTs have not yet been performed for this application. In this review paper, we give a general overview of SCS use, including stimulation types and novel closed-loop systems, as well as DRGS for treatment of neuropathic pain.

\section{SPINAL CORD STIMULATION: PATIENT SELECTION}

When a patient has failed conservative measures and wishes to pursue SCS as a means of treatment, the first step is a 5-7 day trial with temporary leads. If $>50 \%$ pain relief is achieved with the trial, the patient is considered for permanent implantation (34). In general, SCS devices consist of two parts: electrodes which deliver the electric impulses and an implantable pulse generator (IPG) that serves as the power source and pacemaker. Leads for these devices can either be directly implanted via a small laminectomy to place a paddle, or percutaneously (Figure 1). IPGs may either be rechargeable or non-rechargeable. The physical footprint of the IPG is larger for non-rechargeables, but they have less patient burden and are less expensive. Rechargeable IPGs last two to three times as long as non-rechargeables. Charging IPGs varies based on the amount of energy consumed but in general patients should charge their devices at least once a week for about $1 \mathrm{~h}$ by placing a charger over skin at the battery site. This process can become burdensome and sometimes painful. There are two options for intraoperative feedback required during surgery. Intraoperative mapping establishes stimulation frequencies, amplitude, width, and location and requires patient feedback during the operation. Alternatively, intraoperative electromyography can be used on patients under general anesthesia to predict energy requirements and device placement (35). Either immediately or shortly after the procedure is complete, patients will meet with a companyspecific device representative to program their devices for everyday use.

\section{Patient Selection}

When preparing a patient for SCS, it is important that realistic goals are cooperatively set by provider and patient. Patients are considered "responders" if 50\% or greater pain relief is achieved. A discussion carefully delineating this expectation is essential to success, and patients should not expect to be pain free after the surgery. It is also important to weigh comorbidities when determining if a patient is a candidate for the surgery. Patients with conditions causing immunosuppression or impaired wound healing require careful consideration, though successful implantation is possible (29). Studies have shown permanent pacemakers and implantable cardioverter defibrillators can be safely used in conjunction with SCS systems, though close follow-up and coordination with the patient's cardiologist is recommended (36). Comorbid psychiatric conditions such as major depressive disorder and anxiety disorders, which are particularly common within the chronic pain population, should be similarly optimized prior to surgery to maximize pain relief (37-39). Finally, tobacco use diminishes the responder rates of SCS, and providers should consider discussing smoking cessation with patients prior to impantation (40).

\section{TYPES OF SCS STIMULATION}

\section{Tonic Stimulation}

Tonic stimulation is the conventional waveform used in most initial clinical studies of SCS. This form of SCS employs a consistent, low frequency stimulation generally between 40 and $60 \mathrm{~Hz}$ to generate burning, tingling sensations. These "paresthesias" ideally should overlap the areas of pain to mask and replace the perception of pain at that location (41). The landmark PROCESS clinical trials conducted by Kumar et al. found tonic SCS provided superior pain relief and quality of life as compared to traditional medical management when treating FBSS (14). Since then, multiple RCTs have shown that tonic stimulation improved chronic pain related CRPS and DPN as well $(7,42-44)$. In treating CRPS, Kemler et al. reported greater reductions in the visual analog scale (VAS) for pain when treated 
TABLE 1 | Common chemotherapy agents with neuro-related side effects.

\begin{tabular}{|c|c|c|c|}
\hline Chemotherapy agent & Examples & Common uses & Neuro-related side effects \\
\hline Platinum-containing compounds & Cisplatin Carboplatin Oxaliplatin & $\begin{array}{l}\text { Solid tumor malignancies (non-small cell lung cancer, } \\
\text { testicular cancer, ovarian cancer, bladder cancer) }\end{array}$ & Peripheral neuropathy \\
\hline Vinca alkaloids & Vincristine Vinblastine & $\begin{array}{l}\text { Both hematologic (leukemias, lymphomas) and solid } \\
\text { malignancies (pediatric tumors, breast cancer, germ } \\
\text { cell cancer) }\end{array}$ & $\begin{array}{l}\text { Neurotoxicity, including peripheral } \\
\text { sensory neuropathy } \\
\text { Autonomic dysfunction }\end{array}$ \\
\hline Taxols & Paclitaxel Docetaxel Cabazitaxel & $\begin{array}{l}\text { Breast cancer, ovarian cancer, AIDS-related Kaposi's } \\
\text { sarcoma }\end{array}$ & $\begin{array}{l}\text { Neurotoxicity, including peripheral } \\
\text { sensory neuropathy }\end{array}$ \\
\hline
\end{tabular}

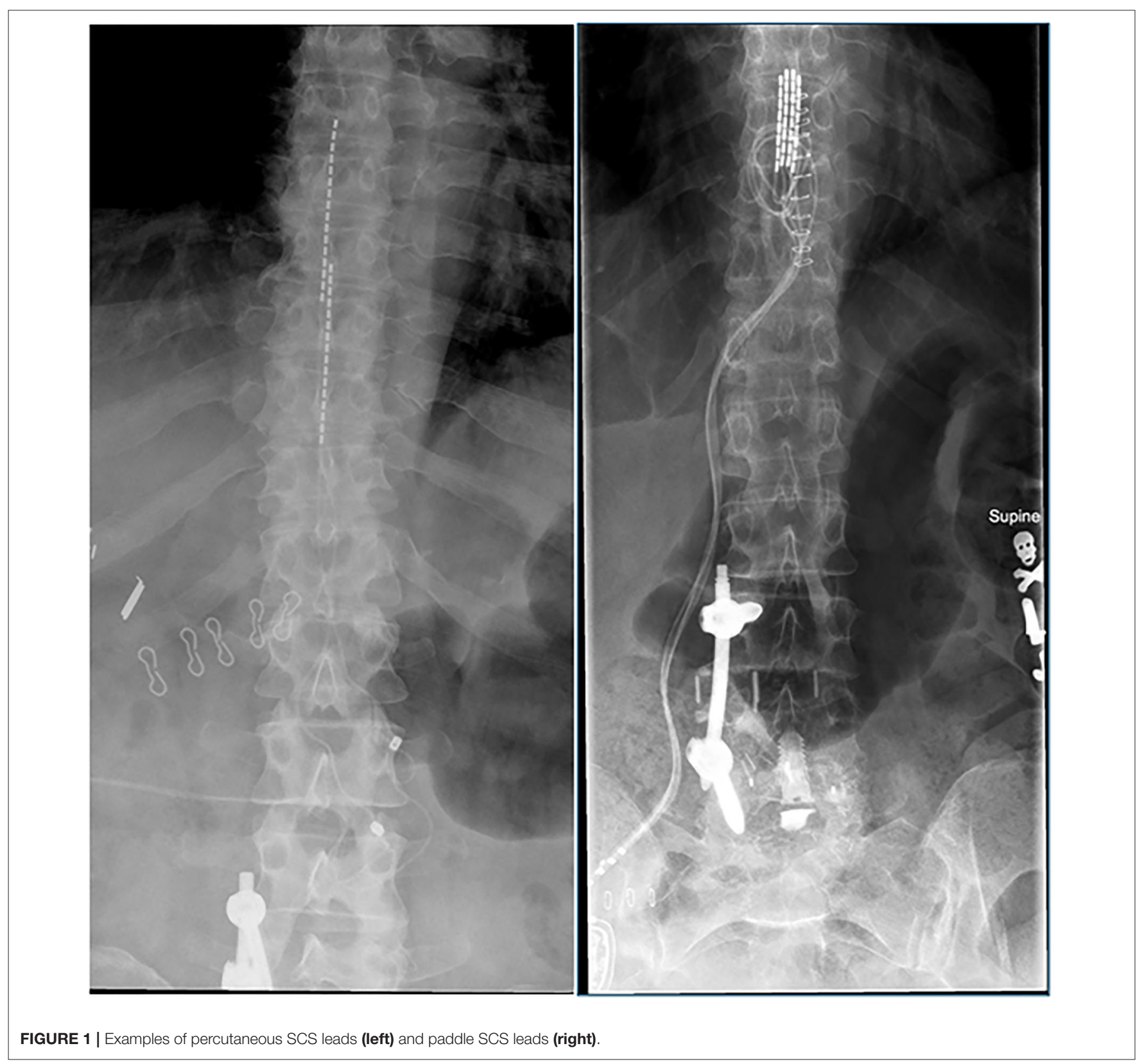

with tonic SCS as compared to physical therapy $(43,44)$. At the 5 -year endpoint of the study, the change in VAS scores remained higher in the SCS group, but the was no longer statistically significant. However, patients who underwent SCS still reported satisfaction with the treatment and stated that they would go through this treatment again for the same results. Tonic SCS 
also demonstrated greater pain relief as compared to traditional medical management of diabetic neuropathy with $60 \%$ of SCS patients meeting success criteria at 6 months as compared to only $5-7 \%$ in the medical management group $(7,42)$.

While the above advancements have yielded relief for many patients, tonic SCS' attainable benefit is variable. For example, this waveform works well for treatment of limb pain but has in the past faced challenges in treating chronic back pain, where adequate paresthesia coverage may be difficult to achieve (4548). Paresthesia is also poorly tolerated in some populations and may not provide pain relief (34). Finally, a number of review papers imply the true mechanisms underlying this waveform are much more complex at both the cortical and segmental levels than previously thought $(49,50)$. Tonic SCS may be further developed to improve patient outcomes as more exact mechanisms are elucidated.

\section{High-Frequency Stimulation}

HFS is a form of SCS that utilizes higher frequencies and lower amplitudes as compared to tonic SCS and was part of the second phase of SCS advancements searching for paresthesiafree SCS. Notably, HFS does not produce paresthesia, making it a treatment option for patients who do not tolerate paresthesia associated with tonic stimulation $(51,52)$. The majority of studies have investigated HFS as a treatment for FBSS and more recently DPN $(12,13,53-55)$. A large RCT was conducted by Kapural et al. comparing HFS at $10,000 \mathrm{kHz}$ (HF10) to tonic SCS found HF10 had a higher response rate at $80 \%$, improvements in opioid consumption rates, disability, and satisfaction at 12 months, and no differences in complication rates (12). Importantly, HF10 also maintained better pain relief in both the back and leg at a 24month follow-up (13). Despite these notable findings, HFS is not well-understood. Proposed mechanisms from various preclinical studies include blockage of axonal conduction, alterations of glial-neuronal interactions, and disruptions of axonal activity (56). Further research is warranted to fully understand its clinical efficacy and expand its usage.

\section{Burst Stimulation}

Burst stimulation involves $500 \mathrm{~Hz}$ of stimulation delivered in bursts of 5 at a frequency of $40 \mathrm{~Hz}$ which is hypothesized to mimic neuronal firing. Burst SCS minimizes paresthesia similarly to HFS and thus can be utilized in patients who do not tolerate this $(10,11)$. Multiple studies support that burst SCS produces similar, if not superior, pain relief as compared to tonic SCS (10, $11,57)$. In the SUNBURST RCT, burst SCS produced superior results to tonic SCS for the treatment of FBSS or neuropathic radicular pain, such that an intention-to-treat analysis found burst stimulation to be non-inferior $(p<0.001)$ and superior ( $p=0.017)$ to tonic stimulation (58). Furthermore, patients demonstrated a clear preference for the burst SCS (70.8\%) which was due in part to improved pain relief reported by some patients; this preference was maintained at the one-year follow-up (58). Smaller studies with crossover designs have demonstrated that burst stimulation produces greater improvement in pain scores as compared to tonic stimulation and placebo $(10,57)$.
Interestingly, burst SCS may activate certain pain centers contributing to its analgesic effects. De Ridder et al. demonstrated pain vigilance and awareness which the tonic stimulation and placebo decreased, possibly attributable to increased activation of the dorsal anterior cingulate cortex and right dorsolateral prefrontal cortex observed encephalogram following burst stimulation (10). While this study may have potential confounding effects with the various treatments given, it describes a potential mechanism of action. Further study by De Ridder and colleagues found that burst stimulation also increases activity in other brain regions like the pregenual anterior cingulate cortex, posterior cingulate cortex, and parahippocampus $(10,47)$. Activation of these combined regions may lead to modulation of descending inhibitory pathways and affective pain perception, which may account for burst SCS' analgesia as well as effects on mood (47).

\section{Closed-Loop SCS Systems}

The intensity of a patient's stimulation varies depending on the distance between the implanted leads and the dorsal columns of the spinal cord. Anything that affects this distance can therefore affect how stimulation is felt, leading to either too much stimulation causing discomfort or too little stimulation to be efficacious (59). This includes positional changes, different activities that may increase the amount of pain felt, and body functions like coughing, sneezing, or laughing. To adjust for these variations, device representatives generally create 2-3 "programs" for patients to toggle between as needed to achieve appropriate stimulation during daily activities. However, closedloop systems will automatically adjust the settings, allowing patients to perform daily activities without having to worry about changing their programs.

In contrast, cardiac pacemakers use feedback from the target organ to alter delivery of electrical impulses. More recent closedloop SCS systems also can automatically adjust stimulation parameters based on feedback mechanisms with the aim of providing more consistent stimulation delivery. These could theoretically abolish the need for multiple programs and decrease the amount of patient participation required for success with SCS, which in turn will foster improved long-term compliance and increase achievable benefits postoperatively. Two feedback mechanisms currently under study for use in closed-loop SCS systems are discussed below.

\section{Accelerometry}

As mentioned above, common daily movements like standing, sitting, walking, or lifting can affect the level of stimulation felt by the patient. Accelerometry can be used to detect changes in posture. A small study of 15 patients showed that $74 \%$ of persons using an SCS system that automatically changed stimulation parameters with positions changes reported that the paresthesias felt were "just right" (60). Following this, Schultz et al. conducted a prospective, randomized study featuring a crossover design (61). This open-label study demonstrated greater pain relief and decreased manual programming requirements when the accelerometry-based SCS system was in use (61). It also demonstrated further evidence that patients were more satisfied 
with less intervention required on her parts. Further, these accelerometry-based systems may be a step in the right direction at achieving the "goldilocks" level of stimulation for patients.

\section{Evoked Compound Action Potentials}

More recently, ECAPs have been used to close the loop. ECAPs represent the cumulative action potential generated in response to stimulation and can be used to quantify a nerve's response to SCS (62). Relying on ECAPs for feedback allows for responses to fluctuate based on the distance between SCS leads and the spinal cord, such as those caused by respiration and cardiac activity. The recent Avalon RCT established the efficacy of an ECAP-based closed-loop system, demonstrating an impressive responder rate of $89.5 \%$ across the 38 subjects completing the full 24-month study and no unanticipated complications or safety concerns (63). However, the single-arm treatment design limits the conclusion providers can draw as to whether the device itself is superior. The Evoke study did feature an open-loop cohort as a control, and significantly more patients implanted with the ECAP-based SCS system were responders at the 3-month and 12month timepoints, respectively (64). Both studies demonstrated similar safety profiles with the ECAP system as compared to open-loop SCS $(63,64)$. While further validation is needed, these novel closed-loop systems may offer solutions to inconsistent stimulation in SCS patients.

\section{DORSAL ROOT GANGLION STIMULATION}

DRGS is a similar method of neuromodulation to SCS with one important difference: the target of the leads. Instead of placing leads to stimulate the dorsal columns (50), percutaneous leads target the dorsal root ganglion (DRG) where sensory neuronal bodies are housed. This theoretically allows for precise targeting of specific pathological neurons that may be firing aberrantly and causing pain. This mode of neuromodulation has been particularly effective for neuropathic pain conditions including postsurgical pain, CRPS, and phantom limb pain (PLP) (65-67). Case reports and retrospective studies have also demonstrated efficacy treating refractory pelvic pain and postherniorrhaphy pain (68-70). The ACCURATE trial conducted by Deer et al. is a prospective RCT that demonstrated evidence that DRGS achieved higher responder rates as compared to SCS for CRPS and lower limb causalgias (65). This study also supported previous findings of more precise paresthesia coverage achievable with DRGS as compared to SCS, particularly in the everchallenging regions to target like the foot and lower back $(65,71,72)$. However, pain relief was also achieved without paresthesia coverage in the ACCURATE trial, and subsequent retrospective studies recommend that DRGS should aim just below the sensory threshold $(73,74)$. Additionally, the absence of a significant epidural space limits variation with position $(65,72)$. The most commonly cited concerns with DRGS are related to the operator, as it is a relatively new procedure that is more technically demanding compared to SCS (66). Other concerns lie in the ability to easily remove the leads. A review of complications following DRG surgery cited lead removal as a common complication (75). Additionally, a case study on 4 patients undergoing DRG for various indications noted lead fracture in all four cases, where 3 of the 4 have undergone previous surgeries (76). Regardless, DRGS is an area of active study.

Research examining DRGS for a variety of pain indications, including cancer-related pain is underway. Studies examining vincristine-induced neuropathy in animal models have demonstrated increased pain tolerance with stimulation of the DRG with ultrasound waves $(77,78)$. An investigation by Koetsier et al. in animal models with DPN demonstrated that DRGS' effects are not related to GABA release from inhibitory neurons in the dorsal horn (79). This suggests that the mechanism by which DRGS alleviates neuropathic pain is distinct from SCS. While confirmatory studies in larger animal and human subjects are still in the pipeline, DRGS may therefore be a particularly fruitful treatment of cancer-related pain in the future.

\section{ALTERNATIVE PROCEDURES}

Other surgical procedures for cancer pain involve interruptions of pain pathways by lesioning nerves, nerve roots, ganglion, etc. These procedures include spinal cordotomy, midline myelotomy, and thalamotomy. Spinal cordotomy is the most common and it eliminates pain sensations from the opposite side of the body (80). Lesion procedures provide immediate pain relief and are useful for patients suffering with malignant pain. However, there are limitations. Cordotomy is irreversible, may result in unpleasant side effects like numbness and weakness and bilateral cases may result in breathing difficulties (80). Most important is that the relief lasts between 3 and 12 months so for nonmalignant pain, this may not be adequate. Risk and benefit profile for myelotomy is similar. Brain ablation results tend to last longer but which patients may benefit is often difficult to predict (80).

\section{COST-EFFECTIVENESS OF SCS}

Chronic pain not only takes a physical and emotional toll on the patient but it also poses a great financial burden for those suffering from it. The cost of chronic pain to society is up to \$USD 635 billion due to patients' excessive utilization of healthcare resources (81). In general, chronic pain patients were found to visit the emergency department more frequently than patients without pain (82-84). More so, the treatment of chronic pain is complex and often results in patients being passed from practice to practice, accumulating bills with little to no relief. Neuromodulation has become an effective alternative treatment for patients refractory to conservative medical management (85). Neuromodulation provides sustainable pain relief for many and subsequently reduces healthcare utilization and unnecessary costs. Kumar et al. demonstrated the incremental cost-effectiveness ratio for SCS ranged from CAN\$ 9,29311,216 (16). The study also showed that SCS provided positive incremental net monetary benefits compared to conventional medical management and the probability of SCS being more 
cost-effective ranged from 75 to $87 \%$ based on pathology (FBSS, CRPS) (16).

\section{CONCLUSION}

Neuropathic pain exacts a significant toll on patients, providers, and health care systems alike. SCS represents a cost-effective and effective treatment for a variety of neuropathic pain indications. Tonic, burst, and HFS have all shown benefit in treating various chronic pain phenotypes, including cancer-related pain and chemotherapy induced neuropathy. Closed-loop SCS systems should be evaluated with cautious optimism as potential future treatments, particularly in patients who have difficulty achieving

\section{REFERENCES}

1. Vos T, Barber RM, Bell B, Bertozzi-Villa A, Biryukov S, Bolliger I, et al. Global, regional, and national incidence, prevalence, and years lived with disability for 301 acute and chronic diseases and injuries in 188 countries, 1990-2013: a systematic analysis for the Global Burden of Disease Study 2013. Lancet. (2015) 386:743-800. doi: 10.1016/S0140-6736(15) 60692-4

2. Nicolaidis S. Neurosurgical treatments of intractable pain. Metabolism. (2010) 59(Suppl. 1):S27-31. doi: 10.1016/j.metabol.2010.07.018

3. Shealy CN, Mortimer JT, Reswick JB. Electrical inhibition of pain by stimulation of the dorsal columns: preliminary clinical report. Anesth Analg. (1967) 46:489-91. doi: 10.1213/00000539-196707000-00025

4. Crapanzano JT, Harrison-Bernard LM, Jones MR, Kaye AD, Richter EO, Potash MN. High frequency spinal cord stimulation for complex regional pain syndrome: a case report. Pain Phys. (2017) 20:E177-82. doi: 10.36076/ppj.2017.1.E177

5. Kumar K, Taylor RS, Jacques L, Eldabe S, Meglio M, Molet J, et al. The effects of spinal cord stimulation in neuropathic pain are sustained: a 24month follow-up of the prospective randomized controlled multicenter trial of the effectiveness of spinal cord stimulation. Neurosurgery. (2008) 63:762-70. doi: 10.1227/01.NEU.0000325731.46702.D9

6. Turner JA, Loeser JD, Deyo RA, Sanders SB. Spinal cord stimulation for patients with failed back surgery syndrome or complex regional pain syndrome: a systematic review of effectiveness and complications. Pain. (2004) 108:137-47. doi: 10.1016/j.pain.2003.12.016

7. Slangen R, Schaper NC, Faber CG, Joosten EA, Dirksen CD, van Dongen RT, et al. Spinal cord stimulation and pain relief in painful diabetic peripheral neuropathy: a prospective two-center randomized controlled trial. Diabetes Care. (2014) 37:3016-24. doi: 10.2337/dc14-0684

8. Klomp HM, Steyerberg EW, Habbema JD, van Urk H. What is the evidence on efficacy of spinal cord stimulation in (subgroups of) patients with critical limb ischemia? Ann Vasc Surg. (2009) 23:355-63. doi: 10.1016/j.avsg.2008.08.016

9. Melzack R, Wall PD. Pain mechanisms: a new theory. Science. (1965) 150:9719. doi: 10.1126/science.150.3699.971

10. De Ridder D, Plazier M, Kamerling N, Menovsky T, Vanneste S. Burst spinal cord stimulation for limb and back pain. World Neurosurg. (2013) 80:6429.e641. doi: 10.1016/j.wneu.2013.01.040

11. De Ridder D, Vanneste S, Plazier M, van der Loo E, Menovsky T. Burst spinal cord stimulation: toward paresthesia-free pain suppression. Neurosurgery. (2010) 66:986-90. doi: 10.1227/01.NEU.0000368153.44883.B3

12. Kapural L, Yu C, Doust MW, Gliner BE, Vallejo R, Sitzman BT, et al. Novel $10-\mathrm{kHz}$ High-frequency therapy (HF10 Therapy) is superior to traditional low-frequency spinal cord stimulation for the treatment of chronic back and leg pain: the SENZA-RCT randomized controlled trial. Anesthesiology. (2015) 123:851-60. doi: 10.1097/ALN.0000000000000774

13. Kapural L, Yu C, Doust MW, Gliner BE, Vallejo R, Sitzman BT, et al. Comparison of $10-\mathrm{kHz}$ high-frequency and traditional low-frequency spinal cord stimulation for the treatment of chronic back and leg pain: 24-month consistent therapeutic stimulation levels. Finally, the newer DRGS is emerging as an additional therapy for those wishing to more precisely target dysfunctional neurons to mitigate pain. As research continues and neuromodulatory techniques, so too will the pain relief and disability endured by chronic pain patients.

\section{AUTHOR CONTRIBUTIONS}

JP designed the manuscript, provided clinical expertise, and edited the manuscript. BS drafted the manuscript with help from JB and OK. All authors approved the final manuscript. results from a multicenter, randomized, controlled pivotal trial. Neurosurgery. (2016) 79:667-77. doi: 10.1227/NEU.0000000000001418

14. Kumar K, Taylor RS, Jacques L, Eldabe S, Meglio M, Molet J, et al. Spinal cord stimulation versus conventional medical management for neuropathic pain: a multicentre randomised controlled trial in patients with failed back surgery syndrome. Pain. (2007) 132:179-88. doi: 10.1016/j.pain.2007.07.028

15. Sanders RA, Moeschler SM, Gazelka HM, Lamer TJ, Wang Z, Qu W, et al. Patient outcomes and spinal cord stimulation: a retrospective case series evaluating patient satisfaction, pain scores, and opioid requirements. Pain Pract. (2016) 16:899-904. doi: 10.1111/papr.12340

16. Kumar K, Rizvi S. Cost-effectiveness of spinal cord stimulation therapy in management of chronic pain. Pain Med. (2013) 14:1631-49. doi: $10.1111 /$ pme. 12146

17. Taylor RS, Ryan J, O’Donnell R, Eldabe S, Kumar K, North RB. The costeffectiveness of spinal cord stimulation in the treatment of failed back surgery syndrome. Clin J Pain. (2010) 26:463-9. doi: 10.1097/AJP.0b013e3181daccec

18. Gee L, Smith HC, Ghulam-Jelani Z, Khan H, Prusik J, Feustel PJ, et al. Spinal cord stimulation for the treatment of chronic pain reduces opioid use and results in superior clinical outcomes when used without opioids. Neurosurgery. (2019) 84:217-26. doi: 10.1093/neuros/nyy065

19. Khan H, Pilitsis JG, Prusik J, Smith H, McCallum SE. Pain remission at one-year follow-up with spinal cord stimulation. Neuromodulation. (2018) 21:101-5. doi: 10.1111/ner.12711

20. North RB, Kidd D, Shipley J, Taylor RS. Spinal cord stimulation versus reoperation for failed back surgery syndrome: a cost effectiveness and cost utility analysis based on a randomized, controlled trial. Neurosurgery. (2007) 61:361-8. doi: 10.1227/01.NEU.0000255522.42579.EA

21. Neufeld NJ, Elnahal SM, Alvarez RH. Cancer pain: a review of epidemiology, clinical quality and value impact. Future Oncol. (2017) 13:833-841. doi: $10.2217 /$ fon-2016-0423

22. Abd-Elsayed A, Schiavoni N, Sachdeva H. Efficacy of spinal cord stimulators in treating peripheral neuropathy: a case series. J Clin Anesth. (2016) 28:74-7. doi: 10.1016/j.jclinane.2015.08.011

23. Cata JP, Cordella JV, Burton AW, Hassenbusch SJ, Weng HR, Dougherty PM. Spinal cord stimulation relieves chemotherapy-induced pain: a clinical case report. J Pain Symptom Manage. (2004) 27:72-8. doi: 10.1016/j.jpainsymman.2003.05.007

24. Elahi F, Callahan D, Greenlee J, Dann TL. Pudendal entrapment neuropathy: a rare complication of pelvic radiation therapy. Pain Phys. (2013) 16:E793-97. doi: 10.36076/ppj.2013/16/E793

25. Hamid B, Haider N. Spinal cord stimulator relieves neuropathic pain in a patient with radiation-induced transverse myelitis. Pain Pract. (2007) 7:345-7. doi: 10.1111/j.1533-2500.2007.00148.x

26. Lee MG, Choi SS, Lee MK, Kong MH, Lee IO, Oh HR. Thoracic spinal cord stimulation for neuropathic pain after spinal meningioma removal: a case report. Clin J Pain. (2009) 25:167-9. doi: 10.1097/AJP.0b013e3181839ad8

27. Yakovlev AE, Ellias Y. Spinal cord stimulation as a treatment option for intractable neuropathic cancer pain. Clin Med Res. (2008) 6:103-6. doi: $10.3121 / \mathrm{cmr} .2008 .813$ 
28. Ahmad I, Ahmed MM, Ahsraf MF, Naeem A, Tasleem A, Ahmed M, et al. Pain management in metastatic bone disease: a literature review. Cureus. (2018) 10:e3286. doi: 10.7759/cureus.3286

29. Hagedorn JM, Pittelkow TP, Hunt CL, D’Souza RS, Lamer TJ. Current perspectives on spinal cord stimulation for the treatment of cancer pain.J Pain Res. (2020) 13:3295-305. doi: 10.2147/JPR.S263857

30. Pike CT, Birnbaum HG, Muehlenbein CE, Pohl GM, Natale RB. Healthcare costs and workloss burden of patients with chemotherapyassociated peripheral neuropathy in breast, ovarian, head and neck, and nonsmall cell lung cancer. Chemother Res Pract. (2012) 2012:913848. doi: 10.1155/2012/913848

31. Forsyth PA, Balmaceda C, Peterson K, Seidman AD, Brasher P, DeAngelis LM. Prospective study of paclitaxel-induced peripheral neuropathy with quantitative sensory testing. J Neurooncol. (1997) 35:47-53. doi: 10.1023/A:1005805907311

32. Holland JF, Scharlau C, Gailani S, Krant MJ, Olson KB, Horton J, et al. Vincristine treatment of advanced cancer: a cooperative study of 392 cases. Cancer Res. (1973) 33:1258-64.

33. Weiss HD, Walker MD, Wiernik PH. Neurotoxicity of commonly used antineoplastic agents (first of two parts). N Engl J Med. (1974) 291:75-81. doi: 10.1056/NEJM197407112910205

34. Song JJ, Popescu A, Bell RL. Present and potential use of spinal cord stimulation to control chronic pain. Pain Phys. (2014) 17:235-46. doi: $10.36076 /$ ppj.2014/17/234

35. Collison C, Prusik J, Paniccioli S, Briotte M, Grey R, Feustel P, et al. Prospective study of the use of intraoperative neuromonitoring in determining postoperative energy requirements and physiologic midline in spinal cord stimulation. Neuromodulation. (2017) 20:575-81. doi: 10.1111/ner.12590

36. Patel J, DeFrancesch F, Smith C. Spinal cord stimulation patients with permanent pacemakers and defibrillators. Pain medicine. (2018) 19:1693-94. doi: $10.1093 / \mathrm{pm} / \mathrm{pny} 049$

37. Andrade L, Caraveo-Anduaga JJ, Berglund P, Bijl RV, De Graaf R, Vollebergh W, et al. The epidemiology of major depressive episodes: results from the International Consortium of Psychiatric Epidemiology (ICPE) Surveys. Int $J$ Methods Psychiatr Res. (2003) 12:3-21. doi: 10.1002/mpr.138

38. Bandelow B, Michaelis S. Epidemiology of anxiety disorders in the 21st century. Dial Clin Neurosci. (2015) 17:327-35. doi: 10.31887/DCNS.2015.17.3/bbandelow

39. Menendez ME, Neuhaus V, Bot AG, Ring D, Cha TD. Psychiatric disorders and major spine surgery: epidemiology and perioperative outcomes. Spine. (2014) 39:E111-22. doi: 10.1097/BRS.0000000000000064

40. Hooten WM, Moman RN, Dvorkin J, Pollard EM, Wonderman R, Murad $\mathrm{MH}$. Prevalence of smoking in adults with spinal cord stimulators: a systematic review and meta-analysis. Reg Anesth Pain Med. (2020) 45:214-8. doi: 10.1136/rapm-2019-100996

41. Atkinson L, Sundaraj SR, Brooker C, O'Callaghan J, Teddy P, Salmon J, et al. Recommendations for patient selection in spinal cord stimulation. J Clin Neurosci. (2011) 18:1295-302. doi: 10.1016/j.jocn.2011.02.025

42. de Vos CC, Meier K, Zaalberg PB, Nijhuis HJ, Duyvendak W, Vesper $J$, et al. Spinal cord stimulation in patients with painful diabetic neuropathy: a multicentre randomized clinical trial. Pain. (2014) 155:2426-31. doi: $10.1016 /$ j.pain.2014.08.031

43. Kemler MA, Barendse GA, van Kleef M, de Vet HC, Rijks CP, Furnee CA, et al. Spinal cord stimulation in patients with chronic reflex sympathetic dystrophy. N Engl J Med. (2000) 343:618-24. doi: 10.1056/NEJM200008313430904

44. Kemler MA, de Vet HC, Barendse GA, van den Wildenberg FA, van Kleef M. Effect of spinal cord stimulation for chronic complex regional pain syndrome Type I: five-year final follow-up of patients in a randomized controlled trial. $J$ Neurosurg. (2008) 108:292-8. doi: 10.3171/JNS/2008/108/2/0292

45. Courtney P, Espinet A, Mitchell B, Russo M, Muir A, Verrills P, et al. Improved pain relief with burst spinal cord stimulation for two weeks in patients using tonic stimulation: results from a small clinical study. Neuromodulation. (2015) 18:361-6. doi: 10.1111/ner.12294

46. De Ridder D, Lenders MW, De Vos CC, Dijkstra-Scholten C, Wolters R, Vancamp T, et al. A 2-center comparative study on tonic versus burst spinal cord stimulation: amount of responders and amount of pain suppression. Clin J Pain. (2015) 31:433-7. doi: 10.1097/AJP.0000000000000129
47. De Ridder D, Vanneste S. Burst and tonic spinal cord stimulation: different and common brain mechanisms. Neuromodulation. (2016) 19:47-59. doi: $10.1111 /$ ner. 12368

48. Oakley JC. Spinal cord stimulation in axial low back pain: solving the dilemma. Pain Med. (2006) 7:S58-63. doi: 10.1111/j.1526-4637.2006.00123.x

49. Sdrulla AD, Guan Y, Raja SN. Spinal cord stimulation: clinical efficacy and potential mechanisms. Pain Pract. (2018) 18:1048-67. doi: 10.1111/papr.12692

50. Jensen MP, Brownstone RM. Mechanisms of spinal cord stimulation for the treatment of pain: Still in the dark after 50 years. Eur J Pain. (2019) 23:652-9. doi: $10.1002 /$ ejp. 1336

51. Tiede J, Brown L, Gekht G, Vallejo R, Yearwood T, Morgan D. Novel spinal cord stimulation parameters in patients with predominant back pain. Neuromodulation. (2013) 16:370-5. doi: 10.1111/ner.12032

52. Van Buyten JP, Al-Kaisy A, Smet I, Palmisani S, Smith T. High-frequency spinal cord stimulation for the treatment of chronic back pain patients: results of a prospective multicenter European clinical study. Neuromodulation. (2013) 16:59-65. doi: 10.1111/ner.12006

53. De Andres J, Monsalve-Dolz V, Fabregat-Cid G, Villanueva-Perez V, Harutyunyan A, Asensio-Samper JM, et al. Prospective, randomized blind effect-on-outcome study of conventional vs high-frequency spinal cord stimulation in patients with pain and disability due to failed back surgery syndrome. Pain Med. (2017) 18:2401-21. doi: 10.1093/pm/pnx241

54. Bolash R, Creamer M, Rauck R, Vahedifar P, Calodney A, Fox I, et al. Wireless high-frequency spinal cord stimulation $(10 \mathrm{kHz})$ Compared with multiwaveform low-frequency spinal cord stimulation in the management of chronic pain in failed back surgery syndrome subjects: preliminary results of a multicenter, prospective randomized controlled study. Pain Med. (2019) 20:1971-9. doi: 10.1093/pm/pnz019

55. Petersen EA, Stauss TG, Scowcroft JA, Brooks ES, White JL, Sills SM, et al. Effect of high-frequency $(10-\mathrm{kHz})$ spinal cord stimulation in patients with painful diabetic neuropathy: a randomized clinical trial. JAMA Neurol. (2021) 78:687-98. doi: 10.1001/jamaneurol.2021.0538

56. Linderoth B, Foreman RD. Conventional and novel spinal stimulation algorithms: hypothetical mechanisms of action and comments on outcomes. Neuromodulation. (2017) 20:525-33. doi: 10.1111/ner.12624

57. Schu S, Slotty PJ, Bara G, von Knop M, Edgar D, Vesper J. A prospective, randomised, double-blind, placebo-controlled study to examine the effectiveness of burst spinal cord stimulation patterns for the treatment of failed back surgery syndrome. Neuromodulation. (2014) 17:443-50. doi: $10.1111 /$ ner. 12197

58. Deer T, Slavin KV, Amirdelfan K, North RB, Burton AW, Yearwood TL, et al. Success using neuromodulation with BURST (SUNBURST) study: results from a prospective, randomized controlled trial using a novel burst waveform. Neuromodulation. (2018) 21:56-66. doi: 10.1111/ner.12698

59. Ross E, Abejón D. Improving patient experience with spinal cord stimulation: implications of position-related changes in neurostimulation. Neuromodulation. (2014) 17 Suppl 1:36-41. doi: 10.1111/j.1525-1403.2011.00407.x

60. Schade CM, Schultz DM, Tamayo N, Iyer S, Panken E. Automatic adaptation of neurostimulation therapy in response to changes in patient position: results of the Posture Responsive Spinal Cord Stimulation (PRS) Research Study. Pain Phys. (2011) 14:407-17. doi: 10.36076/ppj.2011/14/407

61. Schultz DM, Webster L, Kosek P, Dar U, Tan Y, Sun M. Sensor-driven positionadaptive spinal cord stimulation for chronic pain. Pain Phys. (2012) 15:1-12. doi: $10.36076 / \mathrm{ppj} \cdot 2012 / 15 / 1$

62. Parker JL, Karantonis DM, Single PS, Obradovic M, Cousins MJ. Compound action potentials recorded in the human spinal cord during neurostimulation for pain relief. Pain. (2012) 153:593-601. doi: 10.1016/j.pain.2011.11.023

63. Brooker C, Russo M, Cousins MJ, Taylor N, Holford L, Martin R, et al. ECAPcontrolled closed-loop spinal cord stimulation efficacy and opioid reduction over 24-months: final results of the prospective, multicenter, open-label Avalon study. Pain Practice. (2021) 19:715-31. doi: 10.1111/papr.13008

64. Mekhail N, Levy RM, Deer TR, Kapural L, Li S, Amirdelfan K, et al. Longterm safety and efficacy of closed-loop spinal cord stimulation to treat chronic back and leg pain (Evoke): a double-blind, randomised, controlled trial. Lancet Neurol. (2020) 19:123-34. doi: 10.1016/S1474-4422(19)30414-4 
65. Deer TR, Levy RM, Kramer J, Poree L, Amirdelfan K, Grigsby E, et al. Dorsal root ganglion stimulation yielded higher treatment success rate for complex regional pain syndrome and causalgia at 3 and 12 months: a randomized comparative trial. Pain. (2017) 158:669-81. doi: 10.1097/j.pain.0000000000000814

66. Harrison C, Epton S, Bojanic S, Green AL, FitzGerald JJ. The efficacy and safety of dorsal root ganglion stimulation as a treatment for neuropathic pain: a literature review. Neuromodulation. (2018) 21:225-33. doi: 10.1111/ner.12685

67. Eldabe S, Burger K, Moser H, Klase D, Schu S, Wahlstedt A, et al. Dorsal Root Ganglion (DRG) stimulation in the treatment of phantom limb pain (PLP). Neuromodulation. (2015) 18:610-6. doi: 10.1111/ner.12338

68. Zuidema X, Breel J, Wille F. S3 dorsal root ganglion/nerve root stimulation for refractory postsurgical perineal pain: technical aspects of anchorless sacral transforaminal lead placement. Case Rep Neurol Med. (2016) 2016:8926578. doi: 10.1155/2016/8926578

69. Rowland DC, Wright D, Moir L, FitzGerald JJ, Green AL. Successful treatment of pelvic girdle pain with dorsal root ganglion stimulation. Br J Neurosurg. (2016) 30:685-6. doi: 10.1080/02688697.2016.1208810

70. Schu S, Gulve A, ElDabe S, Baranidharan G, Wolf K, Demmel W, et al. Spinal cord stimulation of the dorsal root ganglion for groin pain-a retrospective review. Pain Pract. (2015) 15:293-9. doi: 10.1111/papr.12194

71. Deer TR, Grigsby E, Weiner RL, Wilcosky B, Kramer JM. A prospective study of dorsal root ganglion stimulation for the relief of chronic pain. Neuromodulation. (2013) 16:67-71. doi: 10.1111/ner.12013

72. Liem L, Russo M, Huygen FJ, Van Buyten JP, Smet I, Verrills P, et al. A multicenter, prospective trial to assess the safety and performance of the spinal modulation dorsal root ganglion neurostimulator system in the treatment of chronic pain. Neuromodulation. (2013) 16:471-82. doi: 10.1111/ner.12072

73. Mekhail N, Deer TR, Kramer J, Poree L, Amirdelfan K, Grigsby E, et al. Paresthesia-free dorsal root ganglion stimulation: an ACCURATE study subanalysis. Neuromodulation. (2020) 23:185-95. doi: 10.1111/ner.12942

74. Verrills P, Mitchell B, Vivian D, Cusack W, Kramer J. Dorsal root ganglion stimulation is paresthesia-independent: a retrospective study. Neuromodulation. (2019) 22:937-42. doi: 10.1111/ner.12921

75. Sivanesan E, Bicket MC, Cohen SP. Retrospective analysis of complications associated with dorsal root ganglion stimulation for pain relief in the FDA MAUDE database. Reg Anesth Pain Med. (2019) 44:100-6. doi: 10.1136/rapm-2018-000007

76. Chapman KB, Patel KV, van Helmond N, Chien GCC. Dorsal root ganglion stimulation lead fracture within the superficial fascial layers in 4 cases. $A A$ Pract. (2020) 14:e01307. doi: 10.1213/XAA.0000000000001307

77. Hellman A, Maietta T, Byraju K, Linda Park Y, Shao M, Liss A, et al. Low intensity focused ultrasound modulation of vincristine induced neuropathy. Neuroscience. (2020) 430:82-93. doi: 10.1016/j.neuroscience.2020.01.021

78. Youn Y, Hellman A, Walling I, Gee L, Qian J, Burdette C, et al. High-intensity ultrasound treatment for vincristine-induced neuropathic pain. Neurosurgery. (2018) 83:1068-75. doi: 10.1093/neuros/nyx488
79. Koetsier E, Franken G, Debets J, Heijmans L, van Kuijk SMJ, Linderoth $\mathrm{B}$, et al. Mechanism of dorsal root ganglion stimulation for pain relief in painful diabetic polyneuropathy is not dependent on GABA release in the dorsal horn of the spinal cord. CNS Neurosci Ther. (2020) 26:136-43. doi: $10.1111 /$ cns. 13192

80. Thapa D, Rastogi V, Ahuja V. Cancer pain management-current status. J Anaesthesiol Clin Pharmacol. (2011) 27:162-68. doi: 10.4103/0970-9185.81820

81. Gaskin DJ, Richard P. The economic costs of pain in the United States. J Pain. (2012) 13:715-24. doi: 10.1016/j.jpain.2012.03.009

82. Zucco F, Ciampichini R, Lavano A, Costantini A, De Rose M, Poli P, et al. Cost-effectiveness and cost-utility analysis of spinal cord stimulation in patients with failed back surgery syndrome: results from the PRECISE study. Neuromodulation. (2015) 18:266-76. doi: 10.1111/ner.12292

83. Higgins C, Smith BH, Colvin L. Examination of the clinical factors associated with attendance at emergency departments for chronic pain management and the cost of treatment relative to that of other significant medical conditions. Pain. (2021) 162:886-94. doi: 10.1097/j.pain.0000000000002098

84. Friedman BW, Serrano D, Reed M, Diamond M, Lipton RB. Use of the emergency department for severe headache. A population-based study. Headache. (2009) 49:21-30. doi: 10.1111/j.1526-4610.2008.01282.x

85. Mekhail NA, Aeschbach A, Stanton-Hicks M. Cost benefit analysis of neurostimulation for chronic pain. Clin J Pain. (2004) 20:462-8. doi: 10.1097/00002508-200411000-00012

Conflict of Interest: JP was a consultant for Boston Scientific, Nevro, Jazz Pharmaceuticals and Abbott and receives grant support from Medtronic, Boston Scientific, Abbott, Nevro, Jazz Pharmaceuticals, GE Global Research, NIH 2R01CA166379-06, and NIH U44NS115111. She was the medical advisor for Aim Medical Robotics and Karuna and has stock equity.

The remaining authors declare that the research was conducted in the absence of any commercial or financial relationships that could be construed as a potential conflict of interest.

Publisher's Note: All claims expressed in this article are solely those of the authors and do not necessarily represent those of their affiliated organizations, or those of the publisher, the editors and the reviewers. Any product that may be evaluated in this article, or claim that may be made by its manufacturer, is not guaranteed or endorsed by the publisher.

Copyright (C) 2021 Sheldon, Bao, Khazen and Pilitsis. This is an open-access article distributed under the terms of the Creative Commons Attribution License (CC BY). The use, distribution or reproduction in other forums is permitted, provided the original author(s) and the copyright owner(s) are credited and that the original publication in this journal is cited, in accordance with accepted academic practice. No use, distribution or reproduction is permitted which does not comply with these terms. 